\title{
БЕССОЗНАТЕЛЬНОЕ ЗНАНИЕ ПРЕДМЕТА И ЖЕЛАНИЕ АНАЛИТИКА В НАРКОЛОГИЧЕСКОЙ КЛИНИКЕ
}

\section{ОРИГИНАЛ СТАТЬИ}

ROCHA, Lorena Fabiani da ${ }^{1}$

ROCHA, Lorena Fabiani da. Бессознательное знание предмета и желание аналитика в наркологической клинике. Revista Científica Multidisciplinar Núcleo do Conhecimento. 05-й год, Эд. 04, Vol. 01, стр. 152-161. Апрель 2020 года. ISSN: 2448-0959, ссылка для

доступа: https://www.nucleodoconhecimento.com.br/психология/знаю-

\section{бессознательного}

\section{PE3ЮME}

Клиническая помощь пациентам с наркотиками требует, чтобы наблюдались бессознательные размеры испытуемого, который принимал лекарства и сопровождающего аналитика, учитывая, что эти измерения предшествуют и подразумевают состояние пациента в зависимости. Таким образом, эта работа направлена на уточнение психоаналитических точек зрения, которые определяют подход токсикоманофеномена в области ухода. Такие понятия, как "бессознательное" и "аналитическое желание", были приняты для того, чтобы выяснить, как аналитическая ситуация представляет собой индивидуализирующий метод лечения и выступает против классического метода психиатрии. Поэтому подчеркивается наличие у каждого пациента знания о его наркомании, которое не было предсказано медицинской нозологией. Таким образом, психиатрическая техника считается недостаточной и изучается подход, который стремится лучше интерпретировать наркоманию, имея в качестве инструмента для основания желание аналитика. Помимо центральных понятий, приносимых названием, работа также проходит через понятия "язык", "малас в

\footnotetext{
${ }^{1}$ Окончил фракультет психологии.
} 
культуре", "я", "мономания", "кастрация" и "драйв созревания". Исследование началось с библиографического метода исследования, ссылаясь на тему «Наркомания» в сорере психоанализа и классической психиатрии. Использовалась литература освященных авторов, которые перекрестно доверяют таким знаниям, как Фрейд, Лакан и Берчери.

Ключевые слова: Наркомания, анализ, клиническая помощь, классическая психиатрия.

\section{ВВЕДЕНИЕ}

Наркомания является явлением, которое должно быть изучено за пределами практики наркотиков. В связи с этим, психоанализ предполагает этику и действует от бессознательного знания, которое производит jouissance. Открытие этих знаний проистекает из опыта процесса анализа. Таким образом, признавая желание, которое держит последнюю и особую истину предмета, метод, постулируемый Зигмундом Фрейдом, противопоставляется тому, как классическая психиатрия от Пинеля занималась этим явлением до начала века. $\mathrm{XX}$.

Настоящее исследование основано на психоаналитической теории, то есть рассматривает открытие бессознательного знания, которое влияет на говорящего существо индивидуальным образом, что делает историю жизни каждого субъекта специфическим способом обитания языка, в соответствии с его либидинальной экономикой. Этот язык, в свою очередь, заставляет нас населять недомогание культуры и противостоит нам с объектами, предлагаемыми дискурса капиталиста, чтобы буфер непоправимый недостаток, который знаменует собой человеческое существование. В этом смысле желание аналитика бросает вызов дискурсу науки, которая включала в себя тему речи, языка, субъективности. Исходя из этой предпосылки, исследование направлено на ответ на следующий вопрос: что завуалировано наркоманией, и как работает желание аналитика в наркологической клинике? 
Таким образом, цель этой работы состоит в том, чтобы указать, как желание аналитика представляет собой клинический инструмент и как он приближается к интоксикации, от бессознательного и диска. Важность этого исследования заключается в том, чтобы принять явление в его двойной социальной и субъективной ценности, расширение редукционистского зрения и феноменальный подход к теме. Для достижения этой цели метод, используемый в нашем исследовании, был библиографическим исследованием таких известных авторов, как Фрейд, Лакан и Берчери, которые решают проблему наркомании в контексте психоанализа и классической психиатрии. Исследование проводилось в рамках проекта научного посвящения Университета Вейга-деАлмейда (PIC UVA 2019) под руководством профессора и психоаналитика Клары Лециа Инем.

\section{Результаты}

Из настоящего исследования, вывод был получен, что все знания происходит от манипуляции языком, который до него (LACAN, 1954). Речь идет о человеческом языке, по существу символическом и конкретном, так что здесь он имеет исключительное владение смыслом в токсикоманианическом явлении. Таким образом, это библиографическое исследование подтверждает метод, который противостоит нозологической модели психиатрии, путем субъективации рассматриваемого явления.

Было отмечено, что язык имеет приоритет в функционировании субъекта и осуждает интоксикацию как второстепенный процесс. Оттуда понимается, что практика препарата завуалирует истинный симптом с личными интерпретациями пациента с начала его конституции. Таким образом, следует, что императивом лечения является приписывание символики проявлениям предмета (LACAN, 1955), и мы добиваемся этого, символизм, присутствующий в токсикоманреции, говорит о разочаровании пациента по отношению к другому (FREUD, 1927). При этом состояние подчинения больного сначала уточняется, а затем рассматривает практику наркотиков как головоломку. 
Наконец, была отмечена существенная роль желания аналитика в управлении этим явлением. Это потому, что это желание воздерживается, потому что он предлагает себя в качестве места (КВИНЕТ, 2000) для установки созрели желание пациента. Именно в этом направлении указывает желание аналитика: вместо монотомного повторения и короткого замыкания привода, продвигаемого интоксикацией, приводят субъектки к зрелому желанию, которое распознает и инвестирует в себя. Это вопросы, которые перед нами: опьянение языка, где знак не удается и не позволяет телу быть метафоризированы бессознательного знания.

\section{Обсуждения}

\section{ТОКСИКОМАНИЯ КАК ПРОДУКТ СУБЪЕКТИВНОЙ МАЛАЙЗИИ НА МЕСТЕ ЭПИСТЕМОЛОГИЧЕСКОГО ЗНАКА}

Из дискуссии о возможном происхождении религиозности в "Malaise в цивилизации", Фрейд (1930) указывает некоторые бессознательные механизмы, которые человек порождает иметь дело с болью населяющих мир, с которым он обнаруживает, что он не имеет отношения единства, и который представляет собой препятствие в его поисках счастья. Среди этих механизмов участвует интоксикация, как попытка восстановить удовлетворение жил в начале жизни, и что не в состоянии быть восстановлены, приводит к повторению.

Таким образом, мы признаем, что текущее "я" субъекта является то, что развернулось из его детской версии (FREUD, 1930) после разочарования. Однако, собственная личность покрывает сознательный слой, который вместо появляться вопрос как одно, говорит своих ИМПов его ИМПы ульс более пассивно положенные к испытанию рассечения, по мере того как они охраняют желание. Затем токсикоманическое явление принимается по отношению к этим импульсам. Поэтому объективно наблюдать и классифицировать наркопрактику, как предлагает классическая психиатрия, неэффективно. Этот метод приведет аналитика заниматься анализом, когда он приносит препарат в качестве знака 
идентификации. Таким образом, поскольку аналитик не реагирует с места, ожидаемого пациентом, т.е. места обучения, - делая его поступок неизвестным, как то, что скрывается под самим субъектом, существует аналитическая доктрина, в которой находится незаменимый пробел, который противостоит знанию психиатрии, которая уже существует исчерпанной до опыта с пациентом.

Чтобы найти альтернативный путь, понятно, что пациент должен сначала верить в убеждение, что профессионал знает о том, что он приносит, как беспорядок. Однако, только когда аналитик использует такое предположение для того чтобы причинить вопрос узнать причину в себе, то одно находит undoubted успех процедуры.

Здесь понимают, что интоксикация не является симптомом, но она завуалирует символические механизмы, которые уже имеют значение слова и имеют собственное значение (LACAN, 1953). Тем не менее, принимая другие пути, чтобы расшифровать головоломку будет только смущать вещи. Наименование того, что уже несет в себе знак, ставит нас новый путь вне предмета, и, следовательно, без выхода.

Тем не менее - в remora нас Bercherie (1989), Пинель не обойтись без формулирования огромной носографии, что заставило его квалифицировать наркомании, как безумие импульса, мания без бреда, и, наконец, мономания. Однако психоанализ не соглашается с отношением к прекращению понимания наркомании как импульсов нравственного дела, принимая их исключительно чрезмерными запретными и прочными страстями. Хотя токсикоманакт считается попыткой подорвать культуру умеренности импульсов, он не стал доминировать над ними, наоборот, он используется для того, чтобы подняться на более зрелые механизмы. Таким образом, анализ исследует привязанности, отложенные в препарате, и постоянство себя в наркомании воспринимается как эффеект причины, а не как сама причина.

Психиатрия, в свою очередь, воспринимала моральные причины как самые многочисленные и производящие тип «висцерального возмущения» 
(BERCHERIE, 1989), распространяющий безумие импульса облучением в организме. Интересно отметить, что для психоанализа, причина токсикоманофеномена также делает путь облучения, но это значительное облучение цепи, что дискурсивное ядро субъекта путешествовал, пока он не был клинически наблюдается как явление.

В связи с этим, он находится в соображениях Фрейда (1930), который, чтобы выяснить качество того, что действует желание аналитика, наркотиков практика принята в том, что направлено на защиту от разочарования в реальном мире. Эффрективность токсичных веществ заключается в десенсибилизации пациента перед лицом несчастий невротической жизни, так что препарат подрывает химию тела и делает субъект амортизирует даже оставаясь погруженным во враждебный мир кастрации. Таким образом, психоаналитику следует обратить внимание на стойную символику в эффрективности препарата, учитывая, что в борьбе за счастье интоксикация производит немедленное наслаждение и ощущение независимости от внешнего мира, что должно способствовать неудовольствию.

В связи с этим считается, что целью человеческой жизни (FREUD, 1930) является именно поиск счастья и стремление к удовольствию. Тема предполагает успех либидинальной экономики и работает для избежания страданий, направленных на полное удовлетворение. В этом смысле принцип удовольствия диктует маршруты, которые направлены на психический гомеостаз, даже в его самых преувеличенных видимости, такие как опьянение. Таким образом, это явление представляет собой попытку нейтрализовать невроз субъекта, который находится в этом мире, не будучи в состоянии избавиться от него.

Наркотики действуют вместе с импульсами, которые не подчинились цивилизации и взяли запрещенные предметы, чтобы удовлетворить себя. Учитывая эту ассоциацию, аналитическая ситуация воспринимает запрет на импульсы, которые могут быть подавлены, и признает, что этот запрет выходит за рамки правового права, на субъективном и бессознательном уровне. То, что 
сканируется, это Эдиповая и особая история каждого предмета, в которой они наблюдают за символическим запретом и иногда приводят субъекта к восстанию против кастрации импульсов. (FREUD, 1930).

В этой работе признается, что, как основной источник страданий субъекта, человеческие отношения имеют последствия для того, как он имеет дело со своими импульсами. Несмотря на то, что невротик решил пережить любовь (FREUD, 1927), превратности человеческих отношений могут привести к объектному выбору, который обходит его от опасности любви. Пристрастие к препарату фигуры в качестве одного из этих вариантов. Таким образом, он заботится здесь о токсикоманьяк явление как подтип недомогания, что, несмотря на обычно достижения невротики, подвергается каждый по-своему.

Сказав это, психоанализ считает, что номинальный обычай наблюдения наркоторговли в действительности по-прежнему недостаточен для учета последствий реального запрета. Именно в этом смысле аналитическая методика перекладывает свое внимание на местность, которая не заметна на первый взгляд и не гарантирует заблаговременного назначения, поскольку она не связана с установлением себя абсолютным знанием. Таким образом, это не цель с настоящей работой, чтобы нарисовать полный перечень того, как психоаналитические концепции предлагают решение токсикоманьяк вопрос, но, наоборот, чтобы спасти центральное понятие субъекта бессознательного (FREUD, 1900) и как аналитик вызывает его через токсикоманьяк явление.

\section{БЕССОЗНАТЕЛЬНОЕ ЗНАНИЕ ПРЕДМЕТА}

Чтобы найти инструмент, с которым предметом этой работы подошел, "Интерпретация сновидений" (FREUD, 1900, стр. 406) приносит понятия, что психиатрия пинеля не хватает. Здесь основан третий элемент, без которого мы не предлагаем рассматривать вопрос о наркомании. Затем мы берем слово в том, что оно устанавливает само по себе бессознательный язык и себя. Этот элемент может быть представлен актами повторения с символической ценностью речи. В связи с этим, рецидив измянение в снадобьях происходит 
верой вопроса в надежности с которой предмет делает его возродить прошлое соответствие, и указывает к бессознательному языку который лежит в основе этого соответствия.

Чтобы оспорить удовольствие в этом повторении, отношения с объектом рассматривается как безотзывная связь отсутствия объекта (LACAN, 1956). Эта связь между пациентом и объектом не является прямой, а транспонируется через отверстие. Из-за этого, он не может быть принято в качестве центра аналитической ситуации, но он используется для отсутствия, которые будут выявлены в предмете.

Сказав это, аналитик вмешивается его интерпретации не в любой момент, но где производная отсутствие указатель - препарат - имитирует буферизации отверстие. Таким образом, человек непосредственно не нацелен на интоксикацию, а на символический процесс, который он скрывает. Понятие кастрации (LACAN, 1956) затем подошел как развертывание недостаточности показано на знак Другого в конституции субъекта. Таким образом, понятно, что сила лечения в оппортунистических осознание того, что, если даже другой по отношению к которому пациент представил себя, привел его к разочарованию, заменить, кто пытается выполнить свою функцию также не удалось.

Таким образом, принимая бессознательное в качестве причины, аналитик приводит пациента зацикленный на препарат, чтобы заключить, что даже токсичные, когда они делают тело пользуются появляться молчание кастрации, не в состоянии уничтожить последствия его.

Более того, несмотря на то, что объектные отношения считаются принципиально перфорированными, не имея возможности сосредоточиться на них, именно из ямы, которая структурирует поиск в отношениях с препаратом, это желание обнаруживается как истина, где аналитик эффективно встает. Кроме того, необходимо понимать, что сначала желание влияет на субъект и субъект, уже затронутый причиной, влияет и выбирает объект (LACAN, 1958). В этих отношениях, как и у объекта, само желание также не имеет реального 
представителя, однако, поскольку оно находится в предмете сам, а не снаружи, у него есть шансы на более аутентичные выходы для учета кастрации. Затем он основан на связи спячки с наркотиком объекта поощрения желания, не игнорируя, что даже то, что является наиболее подлинным в предмете не достигается беспрепятственно.

Поэтому, как предложено Лакан (1959), это исследование принимает фундаментальную франтазию предмета в качестве верной фрормы объекта отношений. Ценность этой фантазии в подходе к обсуждаемому здесь явлению заключается в том, чтобы продемонстрировать не только кастрированный предмет и препарат, который она использует как объект обструкции, но прежде всего желание, которое двигает его психический аппарат. Будучи в состоянии распомириться в своей фантазии через его желание, предмет может возникнуть как истина, а не эхо желания другого человека, который когда-то пленил его языком. Таким образом, пациент распознает желание вне себя, и что его собственный не допускает объект удовлетворения, таким образом, вступая в другую стадию своей конституции, как: диск созревания.

Кроме того, интоксикация как несовершенная инвестиция, чтобы назвать положение субъекта в символическом мире, открывает пространство для возникновения желания, перед которым этот вопрос будет вновь пытаться назначения, которые также не удастся (КВИНЕТ, 2000). Анализ предоставит субъекту аналитический дискурс, в ходе которого рассматривается эта неосуществимость. То есть, подрыв истинного симптома находится во всех случаях, в предмете себя, как он сохраняет с реальным и с собой оппозицию к тому, что представляет его символически и творчески.

Сказав это, аналитик рекомендует не искоренить практику наркотиков, с тем чтобы найти, где удовлетворение субъекта с объектом первых лож. Выбор препарата, кажется, гарантирует пациенту найти способ наслаждаться, что независимо от того, для кого в один прекрасный день пришел разочарование Другой. Тем не менее, Сантьяго (2001) предлагает, что в токсикоманьяк акт субъект, кажется, не искать замену объекта для его отношения к другому. Таким 
образом, автор утверждает, что так называемый "наркоман" подразумевает принятие фраллического jouissance в качестве решения само по себе, когда он показывает, что он нашел негенитальный объект, который удовлетворяет его поиск и дисквалифицирует кастрации.

Подводя итог, принимая слово субъекта по железной дороге, обнаруживается, что правящий принцип наркопрактики не только показывает максимизацию удовольствия и устранение неудовольствия, как практическая цель, закрытая сама по себе. Существует в то же время диск динамики с объектом, јоuissance, что оправдано в истории - и только там - предмета. Таким образо[...]м, "субъект, как он говорит, может найти полностью свой ответ, его возвращение, его тайну, его тайну, в построенном символе". (LACAN, 1954, р. 252).

\section{АНАЛИСТ}

Вот последний оператор анализа, который мы будем иметь дело с: желание аналитика. После того, как исследование показало, насколько первобытным является сосредоточение внимания на бессознательном знании предмета и его стремлении к тому же качеству, это покажет особенности и последствия этого другого желания. В этом смысле, несмотря на желание аналитика представить себя на протяжении всего анализа, считается, что именно после оппортунистизации появления бессознательного знания он открывает предмету путь к тому, чтобы броситься на другую ступень. Таким образом, после того, как пациент принял лечение за то, что направляет его удовлетворение в препарат его пульсации, аналитик с его внимательным желанием (LACAN, 1960), также провоцирует признание субъекта о характеристиках собственного желания.

Сказав, что после того момента, когда анализатору удалось выдержать аналитический диалог и невозможность назвать свое желательное состояние, он будет вынужден воспринимать это желание как то, что связано законом, как желание Другого. Стремление аналитика подталкивает к нарушению закона Другого в том, что не означает несоблюдения конституционного права общества. В самом деле, он способствует в анализе, de-subjection к символическому закону, 
который в конечном итоге дерегулирования подлинного функционирования этого вопроса. Таким образом, столкнувшись с истинными причинами практики наркотиков, пациент сталкивается с непоследовательностью Другого Закона (КВИНЕТ, 2000), однако, это не оставлено на удачу, так как желание аналитика начинает занимать место беспомощности, но без Другого, без закона.

Таким образом, даже если это желание заменяет непоследовательность, он сам хранит загадку (КВИНЕТ, 2000). Если субъект ищет то, что аналитик думает о своей наркомании или то, что его знания предлагает для этого явления, он / она не найдет решения, что делает невозможным интерпретировать это желание. Это потому, что анализ работает так, что каждый судит для себя, только делая характер этих выборов очевидным, так что субъект не решает по своему собственному невежеству. Таким образом, именно знание предмета обучимо желание аналитика, а не наоборот, как предполагает классическая психиатрия.

Кроме того, аналитическая методика даже не направлена на "лечение наркомании", как желание аналитика в другом месте, кроме исцеления, освобождения, очистки или помощи другим. Она выступает, например, против морального обращения, предложенного Пинельом для того, чтобы отчитаться о переориентации ошибочного разума (BERCHERIE, 1989). В то время как психиатрия была инструментальна в репрессивных учреждениях и идея, что ум пациента был затронут их восприятием, аналитик также рассматривает окружающую среду и психическую реальность субъекта, но делает ставку на пространство речи и (ре) символическую конституцию бессознательного.

Наконец, желание аналитика признает бессознательное желание субъекта, но отличается от него тем, что он не реагирует на любой спрос, и предлагает место для желания субъекта также не премьер, отвечая. Стремление аналитика не говорит о личном желании знать, но это место ноу-менее (LACAN, 1969), позиция, которая существует исключительно для дела. Таким образом, это желание говорит о высшей цели, позволяющей существование, отделяя его от бессознательных связей, зажатых символическим наследством. 


\section{Выводы}

Эта работа провела значительное теоретическое исследование, которое заключает, однако, в краткой идее: что явление имеет историю, и это личная история субъекта, который наркотики себя. Таким образом, желание аналитика является двигателем, а не лечения, но допроса о повторении с прецедентами в сам ретранслятор. Это как и во всем опыте анализа, клиника открытий, но не зная априори или желание исцелить, в котором пациент строит свои собственные пути (LACAN, 1960) для результата повторения. С учетом этого актуальность этой работы извлекается в том, что она повторяет метод, который ценит самостоятельность субъекта в практике наркотиков.

Исследование приводит нас к тому, чтобы побудить, что, как и любой из пациентов, то, что ищет субъекта, который наркотики сам счастье. Принимая это во внимание, какие аналитические вопросы ситуации "перечеркивает по каким параметрам делает поиск предмета? Что он знает о природе этого желаемого счастья, почему он делает то, что он делает для его достижения?»

Таким образом, мы берем на себя актуальность токсикоманианского явления, в котором его изучение способствует социальному вкладу и в клинику один за другим, не давая себя обобщения, даже перед лицом повторения этого явления. Стремление аналитика работает для того, чтобы пролить свет на бессознательное и особое знание. В этом смысле, в той мере, в какой я является примером невежества в предмете, потому что он имеет в виду Другого, более интимная сорера направлена на достижение своей истины. Для этого, следующий путь взят: речь как доступ к бессознательной истине субъекта в условиях опьянения. Таким образом, допускается, что он не знает априори о том, что речь субъекта о (LACAN, 1956), но это берется в качестве маршрута для доступа к за токсикоманом явление. 


\section{ссылки}

BERCHERIE, Paul. Os fundamentos da clínica: história e estrutura do saber psiquiátrico. Rio de Janeiro: Jorge Zahar, 1989.

FREUD, Sigmund. A interpretação dos sonhos, parte I. Edição Standard Brasileira das Obras Completas de Sigmund Freud, vol. IV. Rio de Janeiro: Imago,1996.

A interpretação dos sonhos, parte II. Edição Standard Brasileira das Obras Completas de Sigmund Freud, vol. V. Rio de Janeiro: Imago,1996.

. O Mal Estar na Civilização. Edição Standard Brasileira das Obras Completas de Sigmund Freud, vol. XXI. 2. ed. Rio de Janeiro: Imago, 1988. LACAN, Jacques. O seminário, livro 1: os escritos técnicos de Freud. 2. ed. Rio de Janeiro: Jorge Zahar, 2009.

. O seminário, livro 2: o eu na teoria de Freud e na técnica da psicanálise. 2. ed. Rio de Janeiro: Jorge Zahar, 2010.

. O seminário, livro 4: a relação de objeto. Rio de Janeiro: Jorge Zahar, 1995.

. O seminário, livro 6: o desejo e sua interpretação. 1. ed. Rio de Janeiro: Jorge Zahar, 2016.

O seminário, livro 7: a ética da psicanálise. Rio de Janeiro: Jorge Zahar, 2008

O seminário, livro 11: os quatro conceitos fundamentais da psicanálise. 2. ed. Rio de Janeiro: Jorge Zahar, 2008.

O seminário, livro 17: o avesso da psicanálise. Rio de Janeiro: Jorge Zahar, 1992. 
QUINET, Antonio. A descoberta do inconsciente: do desejo ao sintoma. 7. ed. Rio de Janeiro: Jorge Zahar, 2018.

SANTIAGO, Jésus. A droga do toxicômano: uma parceria cínica na era da ciência. 2. ed. Belo Horizonte: Relicário Edições, 2017.

Отправлено: март 2020 года.

Утверждено: апрель 2020 года. 